\title{
Simulation Analysis of Dispatching Rules for Automated Material Handling Systems and Processing Tools in Semiconductor Fabs
}

\author{
Julie Christopher, Michael E. Kuhl, Karl Hirschman \\ Rochester Institute of Technology \\ Rochester, New York \\ juliech@us.ibm.com; mekeie@rit.edu; kdhemc@rit.edu
}

\begin{abstract}
A critical aspect of semiconductor manufacturing is the design and analysis of material handling and production control polices to optimize fab performance. This research utilizes two simulations of SEMATECH fab data of actual production fabs. The hypothesis of this study is that both vehicle and machine dispatching rules and their interaction will have significant impact on fab performance. To test this hypothesis, a full factorial design experiment is performed. The vehicle and machine dispatching rules as well as their interaction are shown to have a significant impact.
\end{abstract}

\section{INTRODUCTION}

A critical aspect of semiconductor manufacturing is the design and analysis of material handling and production control polices to optimize fab performance. As wafer sizes have increased, semiconductor fabs have moved toward the use of automated material handling systems (AMHS). However, the behavior of AMHS and the effects of AMHS on fab productivity are not well understood.

This research utilizes two simulations of SEMATECH fab data of actual production fabs. Past research has shown independently that both vehicle and machine dispatching rules can have a significant effect on fab performance. Studies that show the significance of vehicle dispatching rules include Lin et al. [1], and Hasenbein et al. [2]. The effect of machine dispatching rules has been even more thoroughly researched. Studies include O'Neil [3] and Mittler and Schoemig [4]. Lee and Maneesavet [5] conclude that a significant interaction can occur between vehicle and machine dispatching rules in a flexible manufacturing environment. However, a semiconductor manufacturing fab is unlike any other manufacturing environment. Guidelines and rules created for other manufacturing environments in general may not apply in the semiconductor industry. Attempting to apply these findings to the semiconductor industry, the hypothesis of this study is that both vehicle and machine dispatching rules and their interaction will have significant impact on fab performance. To test this hypothesis, a full factorial design experiment is performed.

\section{METHODOLOGY}

A set of simulation experiments is conducted on two representative fab types, an ASIC (make-to-stock) type fab and a Make-to-Order fab. The data to model each fab is taken from SEMATECH fab data sets. Since these data sets do not contain layout and AMHS data, a typical fab and material handling system layout is used for each fab, shown in Figure 1.

These experiments consider five machine dispatching rules and seven vehicle-initiated dispatching rules.

Machine dispatching rules are used at a tool to select the next lot in the queue to be processed. The selection of machine dispatching rules is chosen to reflect commonly used rules in research for the semiconductor industry and also those that have been shown to work well in other manufacturing applications. FIFO is chosen as a baseline rule. The machine dispatching rules evaluated are:

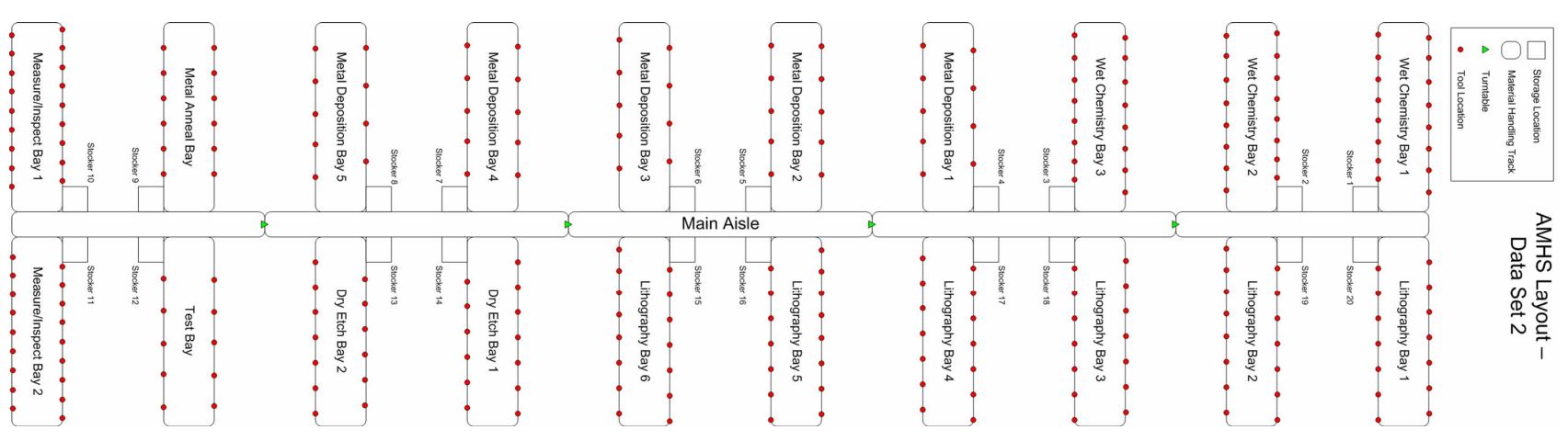

Figure 1. Fab and AMHS Layout for SEMATECH Data Set 2 
- Shortest Processing Time (SPT): The lot with the shortest processing time at the current step will be chosen.

- Earliest Due Date (EDD): The lot that is due first will be chosen.

- $\quad$ First in First Out (FIFO): The first lot that arrived in the queue will be chosen.

- Critical Ratio (CR): The lot with the lowest critical ratio will be chosen.

○ $\mathrm{CR}=($ time until due $) /($ remaining processing time)

- Critical Ratio including Queue time (CRQ): Similar to CR, the lot with the lowest CRQ will be chosen. This calculation, however, includes average queue time and average transit time along with remaining processing time.

○ $\mathrm{CRQ}=($ time until due $) /($ remaining processing time + remaining average queue time + remaining average transit time)

Vehicle-initiated dispatching rules are used by a vehicle to determine the waiting lot that should be picked up next. The vehicle-initiated dispatching rules that are considered are:

- $\quad$ First Encountered First Served (FEFS): The lot which is closest to the vehicle will be chosen.

- $\quad$ First in First Out (FIFO)

- Shortest Travel Time (STT): The lot that had the shortest travel time will be chosen.

- $\quad$ Earliest Due Date (EDD)

- Critical Ratio (CR)

- Critical Ratio including Queue time (CRQ)

- Most Utilized Station (MUS): The lot traveling to the station family that has the highest utilization will be chosen. The goal is to keep bottleneck stations from starving. A simplification made in programming this rule is that the ranking for the utilization of the stations is determined by a run of the model with FIFO used for both the machine and vehicle dispatching rule.

Work center-initiated dispatching rules are used by a lot to determine which idle vehicle should transport it. These rules are only used when there are two or more idle vehicles for a lot to choose from. The work centerinitiated vehicle dispatching rule is set to nearest idle vehicle (NIV) for all runs. This rule simply chooses the closest vehicle if a lot requests a transfer and there are two or more idle vehicles that could fill the request. NIV is chosen because it is the dispatching rule most commonly used.

A full factorial design experiment is conducted to test this hypothesis. Performance indicators of average cycle time, standard deviation of cycle time, average WIP, X Theoretical value, and percentage on time are recorded.
ANOVA tests are performed for each performance indicator on each fab on each dispatching rule combination to test the significance of each factor and their combination. Tukey multiple means comparison tests are performed for each performance indicator on each fab to determine the best combinations of dispatching rules. Results between the two fabs are compared to determine if the same combinations of rules prove to work well for more than just one fab.

\section{RESULTS}

The ANOVA results (Table 1) of this experiment at a $95 \%$ confidence level show that the machine dispatching rule, the vehicle dispatching rule and their interaction are all significant for cycle time in the ASIC fab. ANOVA tests on the remainder of the performance indicators show that the machine dispatching rule, the vehicle dispatching rule and their interaction are all significant for all performance indicators in both fabs.

\begin{tabular}{|r|r|r|r|r|r|}
\hline & DF & \multicolumn{1}{|c|}{ SS } & MS & F & P \\
\hline Vehicle DR & 6 & 309.1 & 51.5 & 86.9 & 0.00 \\
\hline Machine DR & 3 & 162.0 & 54.0 & 91.0 & 0.00 \\
\hline Interaction & 18 & 103.0 & 5.7 & 9.6 & 0.00 \\
\hline Error & 56 & 33.2 & 0.5 & & \\
\hline Total & 83 & 607.4 & & & \\
\hline
\end{tabular}

Table 1: ANOVA of Vehicle and Machine Dispatching Rules on Cycle Time for ASIC Fab

The combination of vehicle and machine dispatching rules can have a significant impact on the overall performance of the fab. There is a reduction in the average cycle time of $20.87 \%$ in the ASIC fab, and $1.77 \%$ in the Make-to-Order fab in the rule combination with the lowest cycle time compared to the FIFO baseline. The presence of an interaction shows that there can be an extra benefit obtained by using rules that work well together. Also, rules that do not work well together can result in significantly poorer performance.

Additional analyses are conducted to identify robust combinations of AMHS and tool dispatching rules among those tested. Table 2 shows the results of the Tukey test done on the top performing dispatching rule combinations for average cycle time on the ASIC fab. The bars under the significance column are drawn across rule combinations which cannot be shown to be statistically significantly different from each other. 


\begin{tabular}{|l|r|r|}
\hline \multicolumn{1}{|c|}{ Dis patching Rule } & $\begin{array}{c}\text { Average Cycle Time } \\
\text { (days) }\end{array}$ & Signific ance \\
\hline VFEFS MFIFO & 15.647 & \\
\hline VMUS MFIFO & 15.78 & \\
\hline VFEFS MCR & 15.907 & \\
\hline VEDD MFIFO & 16.547 & $\mid$ \\
\hline VSTT MFIFO & 16.627 & \\
\hline VFEFS MEDD & 17.383 & \\
\hline
\end{tabular}

Table 2: ASIC Fab Tukey Test on Average Cycle Time for the Best Rule Combinations (Vehicle/Machine Dispatching Rule)

Tukey tests are performed on the remainder of the performance indicators. Table 3 shows the top rule combinations from Tukey tests of all the rule combinations for the ASIC fab. Table 4 shows the top rule combinations from Tukey tests of all the rule combinations for the Make-to-Order fab. Under each performance indicator is the top group of rule combinations for that performance indicator. The rule combinations in each group were not shown to be significantly different from each other.

\begin{tabular}{|c|c|c|c|c|}
\hline $\begin{array}{c}\text { Average } \\
\text { Cycle } \\
\text { Time } \\
\end{array}$ & $\begin{array}{c}\text { Standard } \\
\text { Deviation } \\
\text { of Cycle } \\
\text { Time } \\
\end{array}$ & $\begin{array}{c}\text { Average } \\
\text { WIP }\end{array}$ & $\begin{array}{c}\text { Average X } \\
\text { Theoretical } \\
\text { Value }\end{array}$ & $\begin{array}{c}\text { On } \\
\text { Time } \\
\%\end{array}$ \\
\hline $\begin{array}{l}\text { VFEFS } \\
\text { MFIFO }\end{array}$ & $\begin{array}{l}\text { VFEFS } \\
\text { MCR }\end{array}$ & $\begin{array}{l}\text { VFEFS } \\
\text { MFIFO }\end{array}$ & $\begin{array}{l}\text { VFEFS } \\
\text { MFIFO }\end{array}$ & $\begin{array}{l}\text { VEDD } \\
\text { MFIFO }\end{array}$ \\
\hline $\begin{array}{l}\text { VMUS } \\
\text { MFIFO }\end{array}$ & $\begin{array}{l}\text { VFEFS } \\
\text { MFIFO }\end{array}$ & $\begin{array}{l}\text { VMUS } \\
\text { MFIFO }\end{array}$ & $\begin{array}{l}\text { VMUS } \\
\text { MFIFO }\end{array}$ & $\begin{array}{l}\text { VMUS } \\
\text { MFIFO }\end{array}$ \\
\hline $\begin{array}{l}\text { VFEFS } \\
\text { MCR }\end{array}$ & $\begin{array}{l}\text { VMUS } \\
\text { MFIFO }\end{array}$ & $\begin{array}{l}\text { VFEFS } \\
\text { MCR }\end{array}$ & $\begin{array}{l}\text { VFEFS } \\
\text { MCR }\end{array}$ & $\begin{array}{l}\text { VSTT } \\
\text { MFIFO }\end{array}$ \\
\hline $\begin{array}{l}\text { VEDD } \\
\text { MFIFO }\end{array}$ & $\begin{array}{l}\text { VSTT } \\
\text { MFIFO }\end{array}$ & $\begin{array}{l}\text { VEDD } \\
\text { MFIFO }\end{array}$ & $\begin{array}{l}\text { VEDD } \\
\text { MFIFO }\end{array}$ & $\begin{array}{l}\text { VFEFS } \\
\text { MEDD }\end{array}$ \\
\hline $\begin{array}{l}\text { VSTT } \\
\text { MFIFO }\end{array}$ & $\begin{array}{l}\text { VEDD } \\
\text { MFIFO }\end{array}$ & $\begin{array}{l}\text { VSTT } \\
\text { MFIFO }\end{array}$ & $\begin{array}{l}\text { VSTT } \\
\text { MFIFO }\end{array}$ & \\
\hline
\end{tabular}

Table 3: Best Rule Combinations for ASIC Fab (Vehicle/Machine Dispatching Rule)

\begin{tabular}{|c|l|l|l|l|}
\hline $\begin{array}{c}\text { Average } \\
\text { Cycle } \\
\text { Time }\end{array}$ & $\begin{array}{c}\text { Standard } \\
\text { Deviation } \\
\text { of Cycle } \\
\text { Time }\end{array}$ & $\begin{array}{c}\text { Average } \\
\text { WIP }\end{array}$ & $\begin{array}{c}\text { Average X } \\
\text { Theoretical } \\
\text { Value }\end{array}$ & $\begin{array}{c}\text { On } \\
\text { Time \% }\end{array}$ \\
\hline $\begin{array}{c}\text { VFEFS } \\
\text { MFIFO }\end{array}$ & $\begin{array}{l}\text { VCR } \\
\text { MFIFO }\end{array}$ & $\begin{array}{c}\text { VFEFS } \\
\text { MFIFO }\end{array}$ & $\begin{array}{c}\text { VFEFS } \\
\text { MFIFO }\end{array}$ & $\begin{array}{c}\text { VFEFS } \\
\text { MFIFO }\end{array}$ \\
\hline & VCRQ & & & VCRQ \\
& MFIFO & & & MFIFO \\
\hline & VFEFS & & & VCR \\
& MFIFO & & & MFIFO \\
\hline & & & & VMUS \\
& & & & MFIFO \\
\hline
\end{tabular}

Table 4: Best Rule Combinations for Make-to-Order Fab (Vehicle/Machine Dispatching Rule)
For the ASIC fab, the most robust dispatching rules include: Vehicle EDD with Machine FIFO, Vehicle STT with Machine FIFO, and Vehicle MUS with Machine FIFO. For the Make-to-Order fab the most robust combination of dispatching rules is Vehicle FEFS with Machine FIFO.

\section{CONCLUSION}

The dispatching rules experiment results show that for both the ASIC and Make-to-Order fabs tool dispatching rules, AMHS vehicle dispatching rules and their interactions are statistically significant for all the performance indicators tested. The significance of the interaction displays that an extra benefit may be obtained by choosing good combinations of rules. Also, rules that do not work well together can show a worse performance than expected. The overall results of this study indicate that AMHS and tool dispatching rules must be considered together when trying to optimize fab performance.

The interaction between machine and vehicle dispatching rules appears in both of the fabs studied. This shows that it is possible for the interaction to exist, but does not guarantee that it will always be present. A case where the interaction may not be present is if the AMHS is extremely over or under utilized. If the AMHS is under utilized, there will always be a vehicle available to pick up a lot, and no vehicle dispatching rule will be needed for vehicle selection. Because of this, the vehicle dispatching rule, and hence the interaction, will not be significant. If the AMHS is over utilized, very long queues will form for vehicles. The tools will be starved of work waiting for the vehicles to transport the lots. Since there will be no queues in front the each tool, a machine dispatching rule will not be needed. The machine dispatching rule, and the interaction, will not be significant. Even though the interaction will not hold true in each and every case, each fab has the possibility of added benefits or harm, and the interaction effect should be studied closely to optimize fab performance.

The Tukey tests are performed to determine which combinations of rules give the best performance. These tests are performed on both fabs to determine if the results can be generalized. Three optimal rule combinations are found for the ASIC fab that can not be differentiated statistically, and one optimal rule combination is found for the make-to-order fab. The optimal rule combination for the make-to-order fab, vehicle FEFS and machine FIFO, does not appear in the group of optimal rules for the ASIC fab. However, it is very close to the top group in the ASIC fab, appearing in the top significance level for four out of the five dispatching rules. One of the top rules for the ASIC fab, vehicle STT and machine FIFO, does not even make it to the last Tukey test for the top six rules in the make-to-order fab. This shows that while vehicle FEFS and machine FIFO is shown to be robust for the two fabs, the optimal combination of rules is highly 
dependent on the specific fab. A combination of rules that work well for all fabs in general can not be determined from these experiments.

Although most of the machine dispatching rules tested have an identical counterpart in the vehicle dispatching rules that are tested, none of the top dispatching rule combinations uses the same rule for both the machine rule and the vehicle rule. Is should not be assumed that a dispatching rule that works well in a fab as the machine dispatching rule should also be used for the vehicle dispatching rule of a new AMHS.

\section{REFERENCES}

[1] Lin, J. T., Wang, F., \& Yen, P., "Simulation analysis of dispatching rules for an automated interbay material handling system in wafer fab," International Journal of Production Research, 39(6), 1221-1238, April 2001.

[2] Hasenbein, J., Sigireddy, S., \& Wright, R., "Taking a queue from simulation: The many rules of scheduling semiconductor material handling," IIE Transactions, 36(8), 39-43. August 2004

[3] O'Neil, "Performance evaluation of lot dispatching and scheduling algorithms through discrete event simulation," in Proceedings of the 3rd Annual International Semiconductor Manufactoring Science Symposium held in conjunction with SEMICON/West, May 20-22, 1991, pp. 21-24.

[4] Mittler, M., \& Schoemig, A. K., "Comparison of dispatching rules for semiconductor manufacturing using large facility models," in Winter Simulation Conference Proceedings, December 5-8, 1999, pp. 709-713.

[5] Lee, J., \& Maneesavet, R., "Dispatching rail-guided vehicles and scheduling jobs in a flexible manufacturing system," International Journal of Production Research, 37(1), pp. 111-123, January 1999.

\section{AUTHOR BIOGRAPHIES}

Julie Christopher completed this work as part of her Master of Science degree in Industrial Engineering at Rochester Institute of Technology. She is currently an Industrial Engineer at IBM in Fishkill, NY.

Michael E. Kuhl is an associate professor in the Industrial \& Systems Engineering Department at Rochester Institute of Technology. His research interests include modeling and simulation of semiconductor manufacturing facilities.
Karl Hirschman is an associate professor in the Microelectronics Engineering Department at Rochester Institute of Technology. His research interests are in the areas of Si-based optoelectronics, integration of novel device structures in silicon technology, and quality engineering for process capability improvement. 